\title{
The Cognitive Ergonomics and the Articulation of the Functions of Industrial Products ${ }^{1}$
}

\author{
Sabrina Talita Oliveira ${ }^{\mathrm{a},{ }^{*}}$ and Adriano Heemann ${ }^{\mathrm{b}}$ \\ ${ }^{a}$ Design Department - Federal University of Parana, Curitiba, Paraná, Brazil \\ ${ }^{\mathrm{b}}$ Post-Graduate Program in Design, Federal University of Parana, Curitiba, Paraná, Brazil
}

\begin{abstract}
The sustainable development is a challenge to all areas of knowledge. In the field of design, it motivates an enhanced discussion about the functions of systems, products and services. Accordingly, this paper presents a theoretical contribution to the sustainable articulation of the functions of industrial products from principles of cognitive ergonomics. This paper is based on an exploratory literature about the functions of industrial products and further study of the relationship between man and object of Cognitive Ergonomics, specifically linked the aesthetic perception and symbolic. Presents qualitative results of this correlation, which indicates the feasibility of a better articulation in product development. The paper argues that in the practical field of design, the best articulation of the functions may influence the effectiveness of product performance in its relationship with the user. Already, on theoretical grounds, this new articulation can help designers to understand the nature of the transdisciplinary functions and the insights into product design.
\end{abstract}

Keywords: Sustainable Development, Aesthetical Function, Practical Function, Symbolical Function, Design

\section{Introduction}

The design of industrial products is strongly influenced by the definition of its functions. Complex products perform several functions that are configured by designers and other professionals during product development. The better articulation of the functions may improve the user experience, but this subject is still little investigated in the theoretical fields of design.

This paper proposes a contribution to better articulation of the functions of systems, products and services. Presents a literature analysis as well as information synthesis about cognitive ergonomics principles concerning the aesthetic perception and symbolic of industrial products and Gestalt Theory.

This exploratory qualitative review discusses the three functions of industrial products [2]. Explains the principles of Cognitive Ergonomics, relative symbolic and aesthetic perception of the user. Correlates these principles to Gestalt Theory [3].
To configure the functions of industrial products in an inseparable and transdisciplinary way may contribute to the sustainable product design. However, from the theoretical results presented, the link between the functions of industrial products and the Cognitive Ergonomics is evident. The symbolic function is activated when are considered aspects aesthetic, morphological and structural of products arising from the aesthetic and practical functions. That is, there are implications from one function to another. And the link between them may be principles of perceptual organization based on Gestalt.

The principles of Gestalt, as a means of articulating the aesthetic, symbolical and practical function, enables design students and professionals to better organize the configuration elements of the product through the principles of the perceptual configuration such as units, segregation, unification, closure and good continuation.

In design, the configuration of industrial products is justified by the definition of practical, aesthetical and symbolical functions. However, the good articu-

\footnotetext{
${ }^{1}$ A sustainable approach to the articulation of the functions of industrial products so inseparable and transdisciplinary.

* Address for correspondence: Rua Caetano Costa, Centro - CEP: 89.460-000 - Canoinhas. Santa Catarina. Brasil - Tel.:+55 49 8804-5800

E-mail: binah.oliveira@gmail.com | bina_designxxe@yahoo.com.br
} 
lation of these functions is decisive for the performance of the product by the user.

The articulation between functions of the products can be improved if the functions are considered inseparable and transdisciplinary. Inseparable because one function influences the other, more or less strongly. Transdisciplinary because the relationship of influence transcends the field of design, and this relationship can be better understood if we consider the foundations of Cognitive Ergonomics and applied the principles of Gestalt, those coming from experimental psychology during the formal configuration of the products.

May this knowledge assist academics and professionals to better articulate the functions during the development of products in order to corroborate the compositional organization of the whole product and improve its relationship with the user.

This paper is structured basically in the method of work, review of the design process, the study of functions of industrial products, the principles of Cognitive Ergonomics, discussion of results and finally the conclusion.

\section{Method and Theoretical Development}

\subsection{Method}

The literature review is exploratory qualitative. It refers to the three functions of industrial products [2].

Later, the study of basic functions that configure products seeks the principles of Cognitive Ergonomics inherent to aesthetic and symbolic perception of the user, especially the Gestalt Theory [3] on the theoretical approach of the Visual System of Reading way, closely linked to morphological configuration of the symbol and aesthetics of a product.

Finally, consider the implications of Gestalt and cognitive theories of symbolization on recurrent configuration of the product from the articulation of the transdisciplinary functions.

The results show the correlation and analysis of the functions of the product backed up by Visual Reading of the Principles of Form and cognitive theories, and finally presents proposal for improving the articulation of the functions of industrial products combined with Cognitive Ergonomics.

\subsection{Design Process}

The design process starts from the action of the designer in designing systems, products and services with functions. This process results in the interaction and experimentation by users. Lobach [2] classifies the functions from the use, more specifically: practical function, aesthetical and symbolic function, briefly reviewed below:

- Practical function: "Are all relationships between a product and its users who are at the organic level of the body. Are all the physiological aspects of use.."[2]

- Aesthetical Function: "The aesthetic function of the products is a psychological aspect of sensory perception during use. Creating the aesthetic function of industrial products means designing products according to the perceptual conditions of man." [2]

- Symbolical Function: "An object has a symbolic function when the spirituality of men is stimulated by the perception of this object, to establish links with their previous experiences and sensations." [2]

Once the three functions are understood, it is necessary to have a relation among them in the field of design in order to allow its integral and transdisciplinary use.

\subsection{Principles of Cognitive Ergonomics}

In August 2000, the IEA - International Ergonomics Association adopted the official definition that follows: "Ergonomics (or Human Factors) is a scientific discipline related to understanding the interactions between humans and other elements or systems; and application of theories, principles, data and methods to design in order to optimize human wellbeing and overall system performance. Ergonomists contribute to the planning, design and evaluation of tasks, jobs, products, environments and systems to make them compatible with the needs, abilities and limitations of people. "[1]

Cognitive Ergonomics is one of the areas of specialization in ergonomics. This science works with the "mental processes such as perception, memory, reasoning and motor response as affecting the interactions between humans and other elements of a system." [1]

This study is based on existing knowledge about the relationship between man and objects related to the aesthetic and symbolic perception [1] in order to 
optimize human well-being and effectiveness of communication performance of the product through an ergonomic approach.

\subsection{Aesthetic Perception and Visual Form}

The aesthetic perception can be analyzed by a system called "Reading the Visual Object Shape" coming from the German Gestalt theory, grounded on the field of Psychology of Perceptual Organization of Shape [2]. From Gestalt Theory originated Laws of Experimental Psychology.

- Units: These are elements that shape the way;

- Segregation: is the act of separating, perceiving or identifying the units;

- Unification: the visual cohesion of the form as a function of greater balance and harmony of the formal shape of the object;

- Closing: display spatial features that give a sense of closure of the constituent elements of visual form;

- Good continuation: the visual pattern is caused by settings that have sequences or fluidity.

The Gestalt theory enables the designer to design products endowed with compositional organization. These principles linked to cognitive ergonomics can provide an important articulation of the functions of industrial products, because the use of these laws result in shaping the aesthetic, practical and symbolic products.

\subsection{Symbolic Perception and Cognitive Theories}

The symbolic perception of the object by the individual is directly related to cognitive theories. Thus: "A cognitive approach to motivation is proposed to take into account what is 'going on in the head' of the organism that behaves. According to cognitive theory, there is no automatic connections of stimulus and response, the individual sees the consequences of his behavior because he has acquired and developed information on their experiences". [4]

The individual, from birth, builds knowledge through assimilation and accommodation. [5-6-7] Responsible for the advent of cognitive research, the author observed the behavior of children (Piaget, 1967-1970) and proposed four stages of cognitive development in humans [5-6-7]:

- Sensory-Motor Stage: 0-2 years, when the children acquire knowledge through their own actions that are controlled by immediate sensory input;

- Pre-Operational Stage: pre-school age, 3-6 years, children have symbolic behaviors related intelligence; egocentric thinking and intuitive, centralized thinking, confusion between appearance and reality, absence of the notion of reversibility, transductive reasoning; animism (life to inanimate objects);

- Concrete operational stage: 7-11 years of age, the child begins to deal with concepts such as numbers and relationships. This stage is characterized by a consistent internal logic and the ability for problem-solving;

- Formal operational stage: from 12 years of age, the adolescent begins to reason logically and systematically. This stage is defined by the ability to engage in propositional reasoning. The hypothetical-deductive thinking is the most important aspect presented in this phase, create hypotheses to try to explain and solve problems.

The cognitive theories based on the assumption that everything is assimilated, understood and can be decoded result of the cultural repertoire, a process of appropriation of knowledge and life experiences. Thus, as a result of these aspects is the symbolization.

\section{Discussion}

Articulating the functions of so inseparable and transdisciplinary industrial products can contribute to the field of design. Its possible to identify the link between the functions of industrial products and Cognitive Ergonomics. Thus, this session is to discuss the possibility of a better articulation of the functions of industrial products through a cognitive approach.

The symbolic function is activated when aesthetic, morphological and structural aspects of the products are considered, resulting from the aesthetic function and practical function. That is, a function has an influence on the other and the link between them are the principles of perceptual organization based on Gestalt Theory.

The principles of Gestalt as a means of articulating the aesthetic functions, and symbolic practice enables students and design professionals for better organization of the configuration elements of the product. Through laws of perceptual organization of shape, such as units of the elements that shape the way; seg- 
regation; unification; closure and good continuation, the compositional elements are better suited to the composition of a new product.

However, cognitive theories are also important for better coordination of functions, because knowledge of these involves the application of symbolic function, which can be closely linked with the past experiences of the users. The achievement of this correlation implies that the articulation of the symbolic function of the product is due to their semantic and cultural baggage.

\section{Conclusions}

In the design process, the configuration of industrial products is based on the definition of practical, aesthetic and symbolic functions. Although good coordination of these functions is accepted as a decisive factor for the performance of the product with the user, the effect of this articulation is still a little cleared-up matter in the area of theory and practice of design.

From the theoretical study presented here, the relationship between functions of the products can be improved if the functions are considered so inseparable and transdisciplinary. Inseparable because a function influences the other, more or less strongly. Transdisciplinary because the relationship of influence transcends the field of design and can be best understood if considered Cognitive Ergonomics subsidies and applied principles of Gestalt psychology originated during the formal configuration of the products.

A prior understanding in this sense can help academics and professionals to better articulate functions during the development of products in order to optimize the compositional organization of the whole product and enhance its relationship with the user.

\section{References}

[1] ABERGO, Brazilian Ergonomics Association, Website (2011)

[2] B. Lobach, Industrial Design: bases for product configuration, Edgard Blücher, São Paulo, 2001.

[3] G. Filho, Gestalt do Objeto: Sistema de Leitura Visual da Forma, Escrituras, São Paulo. 2000.

[4] E. Karsaklian, Comportamento do Consumidor, Atlas, São Paulo, 2000.
[5] J. Piaget, The construction reality in the child, Zahar, Rio de Janeiro, 1970

[6] J. Piaget, The reasoning in the child, Record, Rio de Janeiro, 1967.

[7] J. Piaget, The Life and Thought from the Standpoint of Experimental Psychology and Genetic Epistemology, Florense University, Rio de Janeiro, 1972. 